\title{
IMAGEM E SELF EM PLOTINO E JUNG: CONFLUÊNCIAS
}

\author{
IMAGE AND SELF IN PLOTINUS AND JUNG: CONFLUENCES
}

Rafael RAFFAELLI ${ }^{1}$

\begin{abstract}
RESUMO
São analisadas algumas confluências teóricas entre Plotino e Jung, tendo por base os conceitos de imagem e de self (si-mesmo). Plotino é considerado como o descobridor do inconsciente e suas idéias sobre a alma são uma referência básica para a história da psicologia e da psicanálise. Embora não seja habitualmente incluída entre as influências teóricas de Jung, a filosofia plotiniana possui diversos pontos em comum com a psicologia analítica. O conceito de imagem, de importância capital para a teoria junguiana, é altamente altamente relevante em Plotino, o qual propõe uma psicologia do imaginário, quer dizer, um estudo da alma através das imagens. Em relação ao conceito de self, o próprio Jung destaca as intuições de Plotino nesse campo. Jung atribui também a Plotino a primeira formulação do conceito de unus mundus (mundo uno).
\end{abstract}

Palavras-chave: imagem, self, Plotino, Jung.

\begin{abstract}
Some of the theoretical confluences between Plotino and Jung are analyzed, based on the concepts of image and self. Plotinus is considered as the discoverer of the unconscious and his ideas about the soul are a basic reference for the history of psychology and psychoanalysis. Although it is not habitually included among Jung's theoretical influences, the Plotinian phylosophy possesses several points in common with analytical psychology. The concept of image, of capital importance for the Jungian theory, is also highly important in Plotinus, which proposes a psychology of the imaginary, that is, a study of the soul through the images. In relation
\end{abstract}

(1) Doutor em Psicologia Titular UFSC - Universidade Federal de Santa Catarina.

Endereço: Caixa Postal 815 - CEP: 88010-870 - Florianópolis-SC - Tel.: (048) 962-8802

E-mail: raffa@cfh.ufsc.br 
to the concept of self, Jung himself highlights Plotinus' insights on that field. Jung also attributes to Plotinus the first formulation of the concept of unus mundus (united world).

Key-words: image, self, Plotinus, Jung.

Plotino (205-270) é o último filósofo da tradição helenística e o principal representante da corrente filosófica neoplatônica, que vai exercer uma influência marcante no pensamento ocidental.

Suas asserções acerca da alma são referências básicas para o estudioso da história da psicologia e da psicanálise, pois suas idéias repercutiram posteriormente na obra de teóricos do porte de Freud e Jung.

Pois Plotino é considerado por alguns autores (Schwyzer, 1960; Hillman, 1981) como o "descobridor do inconsciente" e o seu conceito de psyque como similar ao de inconsciente coletivo.

E dentre as teorizações junguianas a respeito do inconsciente coletivo a noção que surge como central é a de arquétipo.

O arquétipo para Jung é a parte herdada da psique, que manifesta-se como padrões imagéticos do inconsciente coletivo. Pode ser entendido como o correspondente do inconsciente coletivo aos complexos do inconsciente individual, como imagens atratoras de significado.

A teoria junguiana sobre os arquétipos inicia-se em 1912, quando relata a manifestação de imagens primordiais em pacientes e em sua auto-análise, cujas temáticas centrais repetiam-se nos mitos de diversas culturas. Foi influenciado pelas idéias do historiador neoplatônico Friedrich Creuzer (1771-1858), como ele mesmo coloca:

"O acaso me conduziu ao Simbolismo e Mitologia dos Povos Antigos, de Friedrich Creuzer, e esse livro me entusiasmou". (Jung, 1975:145)

Creuzer foi também editor das Enéadas de Plotino (Plotini Opera omnia), obra impressa em 1835. (cf. Bréhier in Plotino, 1993: I,XLIII)

Em 1919, Jung utiliza pela primeira vez o termo arquétipo, diferenciando-o de suas imagens fenomênicas, como algo irrepresentável em seu conteúdo último, como "formas do instinto". Procura entendê-lo como um conceito psicossomático, que uniria corpo e alma, instinto e imagem, evitando a idéia que as imagens arquetípicas fossem consideradas meros reflexos dos impulsos biológicos. Em 1934, ele define os arquétipos (archetypoi) como os princípios básicos do inconsciente.

Para Jung o arquétipo é uma aptidão imaginária da psique, que reaviva imagens coletivas de significância biológica e histórica como "categorias herdadas". (vide Jung,1981:127; VII,220)

Os arquétipos também se evidenciam nas experiências básicas ou universais da vida (nascimento, ritos de passagem, casamento, maternidade/paternidade, morte) e estão configurados na vida interior da psique através de imagens como a Persona, a Sombra, a sizígia Anima/Animus, a Grande Mãe e o Self (Selbst) ou Si-mesmo, embora possam surgir em infinitas configurações possíveis.

Esses padrões arquetípicos permanecem latentes até que um evento crítico ou uma conjunção de fatores o atualizem, liberando uma força que magnetiza a psique. Os afetos liberados polarizam a vontade, dinamizando 0 eu (ego), conferindo-lhe um objetivo irreprimível. Os períodos de crise são os mais suscetíveis ao surgimento das imagens do inconsciente coletivo.

As qualidades dos arquétipos surgem espontaneamente nos símbolos, nos mitos e nas religiões, aparecendo na psique individual 
como imagens oníricas, delírios, êxtases e na arte. Mas sempre como imagens. Daí o papel vital da imaginação em Jung.

"A imagem é uma expressão concentrada da situação psíquica como um todo(...) tanto inconsciente quanto consciente." (Jung, 1991:418; VI,829)

Na conceituação junguiana, o eu pode ser entendido como um repositório de imagens que se agrupam por significado, oriundas tanto da percepção quanto da memória, formando um complexo de idéias e sentimentos que conferem uma unidade e identidade pragmáticas ao self, em especial nas relações sociais. Mas essa unidade é composta de imagens cambiantes que não possuem realidade em si, o que equivale a dizer que o eu é uma solução de compromisso entre as imagens prevalentes (sensoriais ou mnemônicas) num determinado momento.

"Apesar da aparente unidade do eu, tratase evidentemente de um fator altamente compósito e variado, constituído de imagens provindas das funções sensoriais que transmitem os estímulos tanto de dentro como de fora; consiste igualmente em um imenso aglomerado de imagens resultantes de processos anteriores. (...) Por esta razão não falo simplesmente do eu, mas de um complexo do eu." (Jung, 1982:265; VIII/2,611)

Todas as percepções que chegam ao eu, chegam como imagens. Essas imagens são comparadas com as imagens mnêmicas e agrupadas segundo o sentido prevalente ao eu ou complexo do eu, como Jung prefere denominar. A partir desse ponto ela pode ser conceituada, ou seja, tornar-se objeto do pensamento abstrato. A linguagem é, por sua vez, a expressão da imagem em palavras.

"Mas o que acontece na medula espinhal é transmitido ao eu que percebe, em forma de imagem ou cópia que podemos expressar através de um conceito ou de um nome." (Jung. 1982:163; VIII/2,435,607)
As imagens são qualificadas como primordiais quando apresentam conteúdos arcaicos, isto é, estabelecem relações de significado com motivos mitológicos que são partilhados por toda a Humanidade. Seriam "engramas" mnêmicos resultantes da condensação de processos similares que decorreram ao longo da evolução humana e, por isso, podem ser encontrados em todas as culturas de todas as épocas.

"A imagem primordial é, portanto, expressão condensada do processo vivo." (Jung, 1991:420; VI,834)

Para Jung, a imagem primordial é a origem da idéia, conceito generalizador que está na base dos demais conceitos racionais. Esse princípio racional é, então, uma expressão codificada da imagem primordial.

"A imagem primordial é preâmbulo da idéia, é sua terra-mãe." (Jung, 1991:420; $\mathrm{VI}, 835)$

O símbolo surge através da condensação das idéias derivadas das imagens primordiais, integrando razão e sentimento. Por isso o processo simbólico não é um fato meramente intelectual, alegórico, mas antes um mediador entre os conteúdos inconscientes e a consciência. Além disso, o símbolo propicia o desenvolvimento do auto-conhecimento, pois sintetiza toda uma experiência de vida pessoal dentro de uma representação ou imagem analógica, que pode ser interpretada analiticamente. Entretanto, seu conteúdo não é unívoco, pois não existem imagens que possam ser interpretadas a priori. A diversidade cultural implica numa diversidade simbólica e a dinâmica psíquica dos indivíduos atribui valoração diferenciada às simbologias. Símbolo é aquilo que possui o potencial de alterar a dinâmica do eu, isto é, desconectá-lo das suas imagens habituais e reconectá-lo a um outro patamar de consciência, liberando um quantum de afeto. Desse modo, o símbolo remete a um arquétipo ou imagem primordial, que transcende a consciência, e a imagem, 
como o significante do arquétipo, é a expressão da natureza da alma.

"O si-mesmo pode certamente tornar-se um conteúdo simbólico da consciência, mas é também, sem dúvida, transcendental como grandeza inevitavelmente superior à consciência." (Jung, 1982:161;IX,264)

As Idéias (eide) platônicas são consideradas habitualmente a base do conceito de imagem primordial, somando-se às noções kantianas sobre as categorias perceptivas a priori, bem como ao conceito de idéia ou protótipo em Schopenhauer, como o próprio Jung relata em sua obra Tipos Psicológicos. (vide Jung, 1991:421-422; VI,836-840)

Atribue-se, também, a origem desse conceito a Fílon de Alexandria, ao Corpus Hermeticum, à Dionísio Aeropagita (primitivae formae), a Santo Agostinho (ideae principales) e, ainda, a Jakob Burckhardt (imagens primordiais). Mas, apesar dessas possíveis influências, Jung chega a definir os arquétipos como as idéias platônicas embasadas empiricamente. (vide Jung,1981:57; VII,101 e Jacobi,1986:39-52)

Entretanto, apesar de não ser mencionada explicitamente, a filosofia plotiniana aproximase da psicologia junguiana quanto à questão da imaginação e do si-mesmo (self). Pois Plotino já emprega o termo arquétipo (arcetupon) num sentido propriamente psicológico, ao supor que a elevação do self das imagens aos arquétipos é a meta do ser, que atingiria, assim, o não-ser. (vide Plotino,1993:VI,9,11)

É relevante também o fato de Plotino ter sido incluído por alguns historiadores - seguindo o ponto de vista histórico-religioso e uma metodologia fenomenológica - entre os gnósticos (cf. Torrents, 1990). A ligação dos gnósticos com a obra junguiana é consabida, pois a Gnose e a Alquimia foram as duas maiores fontes de material analítico de Jung (cf. Segal,1995). Por outro lado, encontramos nas Enéadas uma diatribe entitulada Contra os Gnósticos (Plotino,1993:II,9), que demonstra - ao menos no sentido crítico - a convivência das duas correntes filosóficas. O ponto central da discordância seria a justificativa da origem do mal aventada pelos gnósticos, que procederia do próprio Demiurgo; enquanto que Plotino, como a filosofia cristã, afirmava Deus (Uno) como o Bem Supremo, sendo o mal alheio a Ele.

Nossa tarefa, então, é analisar os conceitos de imagem e de self segundo Plotino, comparando-os com a conceituação de Jung, sem a preocupação de buscar exclusivamente as possíveis influências do primeiro sobre o segundo, mas antes as confluências no plano conceitual de ambas as teorias. Pois muitas das intuições de Plotino - um reconhecido mestre espiritual e místico - são, de alguma forma, complementares às de Jung, embora sigam caminhos muito diversos. Plotino egípcio de nascimento, mas habitante de Roma - é um filósofo cujas inquietudes remetem a uma tentativa de síntese entre Platão e Aristóteles, sendo provavelmente influenciado pelo hinduísmo e pelos mistérios de Ísis que Apuleio nos relata no Asinus Aureus (Asno de Ouro).

Já Jung é médico de formação, psicanalista rompido com a ortodoxia freudiana, psicólogo empírico por autodefinição, mas cuja imaginação foi tomada pelos mesmos símbolos que guiaram o pensamento dos antigos. Essa busca junguiana pela natureza da alma através dos sonhos, dos relatos clínicos e da mitologia comparada é similar à empreendida pela filosofia plotiniana pela via da noesis. Vale dizer que Plotino viveu no momento de maior sincretismo e miscigenação cultural e étnica do Império Romano, no início de sua decadência como poder unificador, onde todas as tendências mitológicas, esotéricas, filosóficas e religiosas se uniam e se degladiavam, onde o cristianismo monoteísta começa a mostrar sua força, impondo-se ao paganismo politeísta que agonizava. 
Plotino atribui um papel fundamental para a imaginação na vida psíquica, pois a mesma constitui-se no aspecto distintivo de toda experiência consciente, isto é, propriamente humana.

Propõe, desse modo, uma psicologia imagética, um estudo da alma através de suas imagens. Os epicuristas já postulavam que a alma sensível é basicamente imaginação, a faculdade sem a qual não haveria a experiência consciente; para eles os pensamentos são derivados das sensações provocadas pela ação de um "gerador de imagens" (apud Diógenes Laércio, X, 33-34 in Brun, 1991:31). Dado o primado epistemológico atribuído à aisthesis (sensação ou percepção), entende-se a relevância do conceito de prolepsis (antecipação ou prenoção), visando estabelecer parâmetros para a formação de imagens. A diferença básica é que para Plotino as sensações não são critério de verdade e, por isso, as imagens são emanações de uma realidade transcendente que ele denomina Nous (Inteligência). Similarmente, para os estóicos a Razão (logos) impregna o universo tal como a alma impregna o corpo, quer dizer, é a sua força ativa. Para eles, o corpo produz sensações que são apreendidas pela razão como imagens das coisas; na imaginação (phantasia) as coisas e os pensamentos coincidem por estarem submetidos ao mesmo princípio racional, que é a simpatia cósmica (sympatheia), conceito que Plotino incorporou à sua filosofia. Entretanto, a apreensão ou a ação de captar (katalepsis) uma imagem ainda é tomada como critério de verdade, o que continua a ser oposto à epistemologia plotiniana. Quanto às imagens, partilham todos da conceituação de Aristóteles, para o qual a imaginação (phantasia) funciona como um intermediário entre a percepção (aisthesis) e o pensamento intuitivo (noesis). Apesar dos antagonismos epistemológicos irreconciliáveis, eventualmente todos poderiam concordar que a imaginação é um movimento anímico derivado da percepção, cujo resultado são as imagens, que persistem na memória mesmo após do desaparecimento das sensações que as causaram.

Para Plotino a alma é a expressão ativa da Inteligência que cria o universo sensível (kosmos aisthetos) como uma imagem (eidolon) de si mesma, que assim se reconhece:

"L'âme (...) est une image de l'Intelligence; comme la parole exprimée est l'image du verbe intérieur à l'âme, ainsi elle est le verbe de l'Intelligence et l'activité selon laquelle l'Intelligence émet la vie pour faire subsister les autres êtres." (Plotino, 1993; $\mathrm{V}, 1,3)$

Plotino supõe que a hyle (matéria inteligível) é eidolon (imagem) ou eikon (reflexo) da alma, na acepção platônica (vide Plotino,1993:III,9,3; V,2,1). Com isso aponta para um primado da alma sobre a matéria, pois a matéria corpórea é uma imagem da matéria inteligível refletida na alma. Assim, toda cognição opera através de imagens, que têm seu princípio e seu destino na alma, e a imaginação é a intermediária entre o pensamento e a natureza (vide Plotino,1993:IV,4,1).

Em Jung, o conhecimento também é uma função imagética:

"Todo conhecimento espiritual é uma imagem e uma imaginação." (Jung, 1983:550; $\mathrm{XI}, 889)$

A imagem, para Jung, é a condição do pensamento consciente, possuindo um conteúdo representacional específico radicado no inconsciente, que só pode ser reconhecido pela psique justamente através da imagem que o representa. Mas, em última análise, as imagens seriam produtos dos processos corticais e da ação biológica autônoma.

"Emprego a palavra imagem, aqui, simplesmente no sentido de representação. Uma entidade psíquica só pode ser um conteúdo consciente (...) precisamente quando possui a qualidade de imagem. Por isto chamo 
de imagens a todos os conteúdos conscientes porque são reflexos de processos que ocorrem no cérebro." (Jung, 1982:264; VIII/2,608)

Para Plotino, mesmo a capacidade racional - a parte racional da alma - é vista como uma imaginação conceptual. Essa particularidade é que torna o homem um ser racional, sua capacidade de apreender o pensamento discursivo e transmití-lo numa linguagem convencional.

A atividade da imaginação manifesta-se como um poder de apreensão que distingue o próprio (o sujeito) do outro (o objeto) de modo a torná-lo uma parte de si (da alma) como uma imagem (eidolon).

"Car il ne peut y avoir de pensée sans altérité et identité." (Plotino, 1993; V,1,4)

As potencialidades inatas podem então manifestar-se como uma expressão do Nous (Inteligência), que assim se auto-conhece. As três hipóstases (princípios ou realidades) em Plotino são a Alma do Mundo (psyque tou pantos), a Inteligência (nous) e o Uno (hen). A faculdade cognitiva humana é um atributo da alma agregada ao corpo, que por sua vez é uma imagem do Nous, que por seu turno é uma imagem do Uno, que é 'projetada' sobre o mundo sensível através da alma. Desse modo, o mundo natural é a imagem de seu Criador e a própria matéria (hyle) é uma imagem do ser (on). Essa imagem está em contínua transformação, pois o Uno é um devir que está para além do tempo cronológico e da própria eternidade. (Plotino, 1993:I,8,3; III,7,11; V,1,3; $\mathrm{V}, 8,12)$

Essa seria a contribuição de Plotino à ontologia de Platão e Aristóteles, que entendiam a eternidade como permanência. Para Plotino a eternidade é a vida do Nous e o Uno, como princípio gerador, a transcende. (cf. Aubenque,1981)

Para estabelecer uma conexão entre alma que conhece e o seu objeto, ele introduz o conceito de apreensão consciente, cujo limite inferior é a physis, a natureza que trabalha inconscientemente.

"L'être, dont la vie est perceptible à nos sens, est composé d'êtres qui vivent imperceptiblement pour nous." (Plotino, 1993: IV , 4, 36)

Na visão de Jung:

"O arquétipo é natureza pura, não deturpada e é a natureza que faz com que o homem pronuncie palavras e execute ações de cujo sentido ele não tem consciência. (Jung, 1982:147; VIII/2,412)

Para Plotino, a percepção (aisthesis) humana requer a produção de uma imagem. Essa imagem é produzida pela psyque, que unifica as sensações particulares (táteis, visuais, auditivas, etc.). Dessa forma cria-se a consciência, como lugar de um conteúdo psíquico sintetizado numa imagem, que permite à alma distinguir seu objeto no tempo e no espaço.

De modo semelhante, cria-se uma imaginação conceptual cuja atuação é analítica, quer dizer, disseca a unificação sensorial através do emprego de conceitos racionais.

A consciência humana, então, é formada por essas duas imaginações acopladas, que funcionam como um espelho do real. No entanto, essa imagem especular só é perceptível na total imobilidade, o que equivale a dizer que é o movimento que turva o reflexo da razão.

"Telle l'image dans un miroir, quand sa surface polie et brillante est immobile; le miroir est là, une image se produit; (...) II en est de même dans l'âme; si cette partie de nous-mêmes dans laquelle apparaissent les reflets de la raison et de l'intelligence n'est point agitée, ces reflets y sont visibles; alors non seulement l'intelligence et la raison connaissent, mais en outre l'on a comme une connaissance sensible de cette action." (Plotino, 1993: I,4,10) 
Essas idiossincrasias do sujeito que percebe segundo seus próprios limites também é reconhecida por Jung.

"A consciência é algo semelhante à percepção e, como esta, também está sujeita a condições e a limites (...) pois dependem (...) da condição do sujeito que percebe." (Jung, 1983:553; XI,891)

Para Plotino, um poder de imaginação é necessário para a vida anímica como elo à atuação conjunta dessa dupla faculdade humana de captar o mundo material como essência perceptiva (eide aistheta) e de pensálo segundo conceitos como essência racional (eide noeta), faculdade essa que cria (percebendo e analisando) seus objetos. Devido a isso, o conhecimento humano enquanto razão discursiva (dianoia) nunca atinge a verdade (aletheia), não constituíndo-se numa ciência (episteme), sendo basicamente uma questão de opinião (doxa). A noesis é uma unidade entre o sujeito e o objeto que é só captável através da sua imagem como logismos (raciocínio ou pensamento discursivo). (cf. Peters, 1983)

O processo pelo qual a alma toma consciência formando uma imagem é denominado antilepsis ou 'apreensão consciente'. Esse processo ocorre tanto em relação à percepção quanto à intuição. A atividade antiléptica ou imagética é o centro da ação humana cotidiana, permitindo ao homem separar-se do seu entorno e agir como um indivíduo, um sujeito atuando sobre objetos.

Aquilo que nos distingue dos animais é a dianoia ou razão discursiva. Todavia, não temos consciência nem de todos nossos pensamentos, nem de nossas funções corporais ou rotineiras. Então a consciência só é recuperada por uma imagem mnêmica.

"La mémoire des choses sensibles appartient donc à l'imagination." (Plotino, 1993: IV,3,29)

\section{Em Jung:}

"Percebemos apenas as imagens que nos são transmitidas indiretamente, através de um aparato nervoso complicado. (...) A conseqüência disto é que aquilo que nos parece como uma realidade imediata consiste em imagens cuidadosamente elaboradas e que, por conseguinte, nós só vivemos diretamente em um mundo de imagens. (...) Nós somos subjugados por um mundo que foi criado pornossa psique." (Jung, 1982:332-333; VIII/ 2,745-747)

Por conseguinte, a consciência humana é o acompanhamento de uma sensação ou pensamento por uma imagem, isto é, toda cognição é propriamente imaginária.

Devido a isso, a consciência na filosofia plotiniana é descrita como parakolouthein (seguir junto), enfatizando a dualidade entre a imaginação e o objeto imaginado, permitindo o auto-conhecimento. Assim, a vida psíquica só é possível através da intermediação da imaginação.(cf. Warren, 1966)

Entretanto, Plotino afirma que nem todo pensamento é imagético, pois existem pensamentos racionais inconscientes. A necessidade de imagens é uma característica da apreensão consciente e não engloba todos os pensamentos. Só os pensamentos conscientes necessitam transformar-se em imagens para serem pensados. E, para 0 pensamento discursivo, as imagens são conceituais e não pictóricas, diversamente das imagens advindas da sensação.

Nesse sentido, como já nos referimos, segue a formulação aristotélica, na qual a imaginação (phantasia) é o elo unindo sensação e pensamento.

"Si [comme le dit Aristote] une image accompagne toute pensée (...) le langage, en la développant et en la faisant passer de l'état de pensée à celui d'image, reflète la pensée comme um miroir. (...) Car autre chose est de penser, autre chose de percevoir sa pensée. Nous pensans toujours; mais nous ne percevons pas toujours notre pensée, parce 
que le sujet qui reçoit les pensées reçoit aussi, alternativement, les sensations." (Plotino, 1993: IV,3,30)

Plotino distingue, assim, o pensamento de sua apreensão consciente pois estamos sempre pensando mas nem sempre apreendemos (conscientemente) o que pensamos, ou seja, a alma humana pensa (inconscientemente) sem dar-se conta do que pensa.

Essa é a concepção encampada posteriormente por Leibniz, que ecoa sobre a psicanálise freudiana e também em Jung:

"A psique não coincide com a consciência, mas (...) funciona inconscientemente à semelhança ou diversamente da parte capaz de se tornar consciente." (Jung, 1984:110; VIII/2,362)

Isso significa que o ser humano só está consciente quando uma imagem está presente, tanto de um objeto sensível ou inteligível. A imaginação é o que nos faculta separar o sujeito da consciência dos objetos, senão cairíamos na atividade natural (biológica) inconsciente, incapaz de elevar-se além das aparências sensoriais até a intuição (noesis) das formas primeiras.

Essa diferenciação entre percepção e apercepção e o reconhecimento da existência de pensamentos inconscientes está amplamente de acordo com as concepções junguianas. Para Jung, esses pensamentos agrupam-se em imagens segundo seus significados, em função das finalidades a que se propõem, visando o auto-conhecimento:

"Posso afirmar que se trata de 'processos nucleares' significativos na psique objetiva, de certas imagens de meta que o processo psíquico parece propor a si mesmo por 'ser orientado para um fim'." (Jung, 1994:233-234; $\mathrm{XII,328)}$

Em Plotino, alma é una na sua multiplicidade, pois cada ser é idêntico a todos os demais seres e o todo está em tudo. Logo, pode-se afirmar que 'tudo está em tudo'.
A unidade ou mônada (monas) é semelhante ao Uno e sempre igual a si mesma. O movimento da alma é ocasionado pelas razões seminais (logoi spermatikoi), que são a causa das diferenças individuais. A finalidade da alma de todas as almas - é efetuar a regressão ao Uno através da Inteligência. (cf. Bréhier, 1977:173)

"L'âme (...) ne se fragmente pas pour animer par chacune de ses parties chaque partie du corps; mais toutes les parties vivent par l'âme toute entière, elle est toute présente partout, semblable, par son unité et son omniprésence, au père qui l'a engendrée [l'Intelligence]." (Plotino, 1993; V,1,2)

Para Jung existe a possibilidade de um conhecimento que ultrapasse os limites espácio-temporais. O seu conceito de unus mundus (mundo uno), que apóia a noção de correspondência acausal ou sincronicidade, afirma igualmente a relação intrínseca entre o uno e o múltiplo. Em sua última grande obra, Mysterium Coniunctionis, Jung cita Plotino como uma das origens desse conceito. (Jung, 1985:292; XIV/2,416)

Essa mesma referência já havia sido colocada em seu texto Sincronicidade:

"Também, segundo Plotino, as almas individuais se acham ligadas por uma relação mútua de simpatia ou antipatia, na qual a distância não exerce nenhuma influência." (Jung, 1986:58; XVIII,917)

Nessa concepção, a consciência possui uma dupla função cognitiva e espiritual.

"Os arquétipos (...) são correspondentes complementares do 'mundo exterior' e, por isso mesmo, possuem caráter 'cósmico'. Daí se explica sua numinosidade $e$, concomitantemente, seu 'caráter divino'." (Jung, 1982:186-187; IX/2,305)

Jung reconhece que existe um pensamento primordial - comparável, talvez, à Inteligência plotiniana - inerente à espécie humana, que foi construído e desenvolvido durante a evolução do Homem. Esse 
pensamento foi expresso e memorizado em imagens, que funcionam como guias da psique, como um verdadeiro fio de Ariadne rumo ao centro do labirinto.

"Há um pensamento nas imagens primordiais, nos símbolos, que são mais antigos que o homem histórico e nascidos com ele desde os tempos mais antigos e, eternamente vivos, sobrevivem a todas as gerações e constituem os fundamentos da nossa alma. (...) Para mim, as imagens primordiais são como órgãos psíquicos." (Jung, 1982:352; VIII/2,794)

Esses 'órgãos psíquicos' são - seguindose a metáfora - as 'antenas' da psique humana coletiva, arcabouço de todo imaginário criado pela humanidade, pela qual captam-se e atualizam-se as imagens.

No que se refere ao arquétipo central, o self ou si-mesmo, Jung cita um extenso trecho de Plotino em apoio às suas idéias:

"Encontramos uma concepção paralela [à natureza psicológica do si-mesmo] em Plotino (cerca de 205-270). Assim, diz ele em suas 'Enéadas': 'Sempre que uma alma se conhece, sabe que seu movimento natural não se processa em linha reta, pois sofreu um desvio; mas sabe que descreve um movimento circular em torno de seu princípio interior, em torno de um centro. Mas o centro é aquilo de onde procede o círculo. A alma, portanto, movimentar-se-á em torno de seu centro, isto é, em torno do princípio de onde ela procede. Ela manter-se-á presa a ele; movimentar-se-á em direção a ele, como deveriam fazer todas as almas. Mas só as almas dos deuses se movimentam em direção a ele, e por isso são deuses, pois tudo o que se acha unido a esse centro é, em verdade, deus, ao passo que o que se acha afastado dele é o homem, o homem sem unidade, o homem animal'. Nesta concepção, o ponto é o centro de um círculo que é produzido, de algum modo, pela deambulação da alma em torno dele. Mas o ponto é o 'centro de todas as coisas'; é uma imagem de Deus. É esta a concepção que ainda hoje encontramos na base dos símbolos mandálicos dos sonhos." (Plotino, En.VI,8,1;VI,9 in Jung, 1982:209; IX/2,342)

Para Plotino, o self noético ou imanente (noetike kai psychike), a fonte da vida, não necessita imaginação pois é auto-consciente. A tarefa última da consciência é tornar-se inconsciente num patamar superior de conhecimento, onde a distinção imagética entre sujeito e objeto foi superada e finalmente integrada. A fragmentação do self é total no nível da physis, onde encontra-se num estado de inconsciência de seu potencial cognitivo. Para superá-la, surge a sunaisthesis como a unidade cognitiva básica motivada pela simpatia cósmica (sympatheia) que une o universo num todo integrado. (cf. Warren,1964)

"Car l'intelligence est à la fois une partie de nous-mêmes et un être supérieur auquel nous élevons." (Plotino, 1993: I,1,7)

$\mathrm{Na}$ interpretação de Jung, a conscientização das imagens primordiais, que atuam de forma inconsciente ou préconsciente, é que permite ao homem reconhecer sua própria humanidade:

"Existem arquétipos pré-conscientes que nunca foram conscientes. (...) Só quando o homem possui a capacidade de ser consciente é que se torna verdadeiramente homem." (Jung, 1982:147; VIII/2,412)

E essa humanidade reflete-se em tudo o que a psique pode abarcar:

"O si-mesmo surge em todas as formas, das mais elevadas às mais ínfimas, uma vez que tais formas ultrapassam as fronteiras da personalidade do eu, à maneira de um 'daimon' (demônio socrático)." (Jung, 1982:216; IX/2,356)

Para Plotino o Nous mantém a alma humana permanentemente ligada ao kosmos noetos (universo inteligível), mas como a atenção está distraída pelos objetos sensíveis ela não dá-se conta disso. Quer dizer, embaixo da atividade consciente cotidiana continua a operar inconscientemente o self imanente, o 
inteligível que habita em cada ser. Ontologicamente essa operação pode ser descrita como a unidade entre sujeito e objeto numa realidade existencial, fornecendo as bases epistemológicas para uma abordagem cognitiva da divindade. Assim, o Uno não é um ser, mas antes um processo unificador que nada é em si, apesar de ser em si todos os seres. (Plotino, 1993:V,1,6; VI,8; VI,9)

O self imanente pode tornar-se cônscio para o homem, que assim cumpre uma dupla finalidade: alça a alma humana ao nível do Nous e, ao mesmo tempo, permite que o Nous tome consciência de si mesmo. A palavra a descrever o self é alternadamente psyche ou anthropos, isto é, a realidade ontológica e a consciência humana. O self possui um dinamismo cognitivo perpétuo e surge para o homem como imago Dei, ou seja, a imagem de Deus espelhada na consciência.

“L'âme aussi est animée d'un mouvement éternel. (...) Il est donc nécessaire, pour que nous percevions la présence de ces actions, de tourner nos perceptions vers l'intérieur de nous-mêmes, et d'y maintenir notre attention." (Plotino, 1993:V,1,12)

Em Jung também encontramos o pressuposto de um movimento:

"O processo inconsciente como que se move em espiral em torno de um centro(...). Poderíamos talvez dizer(...)que o centro - em si mesmo incognoscível - age como um imã sobre o material e os processos disparatados do inconsciente, capturando-os pouco a pouco em sua teia de cristal." (Jung, 1994:230; XII,326)

Para Plotino esse centro é Deus. E ele define Deus como "he tou me noein riza", a 'impensável raiz da alma' e, assim, encontrar a si mesmo é conhecer sua origem na contemplação da imagem do Uno, refletida no self através da Inteligência (Nous). (cf. Warren, 1964)

"En dehors de I'Intelligence et autour d'elle circule l'âme; elle regarde en l'Intelligence et, en la contemplant jusque dans son intimité, elle voit par elle le Dieu suprème." (Plotino, 1993: I,8,2)

A consciência poderia ser entendida, então, como um jogo de espelhos onde a fidelidade da imagem seria uma função da clareza da superfície reflexiva. (cf. Plotino, 1993: VI,9,7-9)

"Il faut que, contemplant cet Un qui est en lui-même comme à l'intérieur d'un sanctuaire, et qui reste immobille au delà de tout, nous contemplions les images qui déjà tendent vers l'extérieur (images stables), ou plutôt la première image qui s'est manifestée. (...) Tous les êtres d'ailleurs, tant qu'ils subsistent, produisent nécessairement autour d'eux, de leur propre essence, une réalité qui tend vers l'extérieur et dépend de leur pouvoir actuel; cette réalité est comme une image des êtres dont elle est née." (Plotino, 1993:V,1,6)

A realidade é criada pelo ser como uma imagem na qual ele se insere. Enquanto que para Plotino a crença em Deus é o resultado natural do pensamento que alcança a contemplação da verdade (aletheia), o que interessa a Jung é demonstrar a realidade empírica desses fenômenos e desvinculá-los de toda crença religiosa. Jung também diferencia a imagem de Deus de Deus mesmo, embora por razões diversas das de Plotino. Diz ele:

"O que se pode é constatar que o simbolismo da totalidade psíquica coincide com a imagem divina, embora não se possa demonstrar que uma imagem divina é o próprio Deus ou que o si-mesmo substitui Deus." (Jung, 1982:188; IX/2,308)

Além da separação dos pressupostos teológicos dos psicológicos, Jung dicotomiza a possível interpretação do significado do self em teses materialistas ou espiritualistas:

"Numa interpretação materialista poder-se-ia afirmar que o 'centro' nada mais é do que aquele ponto em que a psique se torna incognoscível, por ser lá que se funde como 
corpo. Numa interpretação espiritualista, inversamente, afirmar-se-ia que o si-mesmo nada mais é do que o espírito, o qual anima a alma e o corpo, irrompendo no tempo e no espaço através desse ponto criativo." (Jung, 1994:233; XII,327)

Para Jung o self pode ser compreendido como a imagem da totalidade da psique, como seu centro e também como símbolo dessa unidade, abrangendo consciente e inconsciente e o próprio eu.

O self, como o arquétipo central, seria um princípio unificador da personalidade, conferindo um sentido às ações do indivíduo e integrando-as num todo coerente, como o lapis alquímico.

Por outro lado, o self é também uma imago Dei, isto é, uma imagem de Deus. Essa imagem seria um símbolo da unidade e da transcendência do universo, a qual realiza a síntese de todas as oposições.

Por isso, Jung recupera a formulação escolástica:

" 'Deus est circulus cuius centrum ubique, circunferentia vero nusquam' [Deus é um círculo cujo centro está em toda parte e cuja periferia não está em lugar algum]." (Jung, 1982:144; IX/2, 237, n.113)

Por conduzir à síntese dos opostos, o self carrega uma conotação tanto do bem (Deus como encarado pelas religiões monoteístas), como do mal, quer dizer, a divindade maligna e destruidora (o Demônio). Devido a essa enantiodromia (relação entre opostos), o símbolo do self é em geral um quatérnio ou quaternidade. Assim, o símbolo cristão da divindade, a Trindade, complementase com o Demônio, o quarto elemento.

"Coincidentia oppositorum (coincidência dos opostos), por meio da qual se exprime a divindade do si-mesmo." (Jung, 1985: 142; $\mathrm{XIV} / 1,171$ )

Nesse sentido, como anteriormente observado em relação aos gnósticos, a filosofia plotiniana afasta-se da concepção de Jung, pela sua crença na divindade como um Bem absoluto.

Para Plotino, porém, essa discussão sobre a origem do mal, como todo conhecimento discursivo, é só uma parte do processo - a parte inferior - da busca intuitiva pelo conhecimento da alma, que vai além do humano:

"Donc il y a une double connaissance de soi-même; ou bien l'on connaît la nature de la pensée discursive de l'âme; ou bien on la dépasse, et l'on se connaît como être conforme à l'intelligence; c'est par elle qu'on se connaît non plus comme homme." (Plotino, 1993: V,3,4)

Para ele a alma é de natureza inteligível, que funciona como um veículo para todos os seres, não é uma exclusividade humana. A ordem do universo é mantida pela ação racional da alma, sendo ela o verdadeiro princípio do mundo. Ela gira ao redor de um ponto central, circularmente, e anima a natureza, possibilitando o movimento e, assim, criando a physis ou o mundo natural. O Uno cria o cosmos sem sair de si mesmo, através da processão ou emanação (proodos), e o cosmos retorna ao Uno por meio da conversão ou retração (epistrophé), num movimento perpétuo que não possui uma gênese no tempo. (cf. Brun,1991)

"Elle est comme le centre dans un cercle: tous les rayons tirés du centre à la circonférence laissent pourtant le centre immobile, bien qu'ils naissent de lui et en tiennent leur être; ils participent du centre, et ce point indivisible est leur origine; mais ils s'avancent au dehors, bien qu'ils y restent attachés." (Plotino, 1993: IV,2,1)

Jung associa essa noção às concepções alquímicas:

"Na filosofia neoplatônica a alma mantém uma relação nítida com a forma esférica. (...) Como no Timeu de Platão, a 'anima mundi' bem como a 'alma do corpo' tem para os 
alquimistas a forma esférica." (Jung, 1994:93; XII,109, n.41)

Plotino incorpora essa noção platônica na sua filosofia:

"Comme notre corps est une partie de l'univers, ainsi notre âme est une partie de l'âme de l'univers". (Platão, Filebo:30 in Plotino, 1993: IV,3,2).

Para Plotino, a psyche tou pantos ou anima mundi possui uma parte voltada à contemplação (theoria) e a outra ligada à ação (praxis) que é a própria natureza (physis). Mas, ao contrário de Platão, a Alma do Mundo plotiniana é a responsável pela produção do mundo sensível que transcorre no tempo, que assim ganha um estatuto de realidade (embora no seu mais baixo nível), não sendo mera fantasmagoria, pois a própria matéria espelha o ser.

Portanto, a alma é una e múltipla e atende à demanda divina por auto-conhecimento.

"Notre âme est chose divine; elle est d'une nature différente de l'être sensible; elle est telle que l'âme universelle." (Plotino, 1993:V,1,10)

Jung reconhece nessas formulações um eco de suas próprias teorias:

"A alma do mundo, portanto, que constitui o princípio dominante de toda a physis, possui uma natureza trina e, visto como para Platão o mundo é um segundo Deus, a alma do mundo constitui uma imagem revelada $e$ desdobrada de Deus." (Jung, 1983:126; XI,187)

Contudo, diversamente de Platão e Plotino, Jung vê nessa noção apenas uma outra imagem de totalidade e não uma substância 'pensante' ou 'consciente' autônoma:

"A alma ou o espírito do mundo, constitui uma projeção do inconsciente. (...) A 'alma' e o 'espírito', isto é, a psique em geral é, em si e por si, totalmente inconsciente enquanto substância." (Jung, 1982:133; IX,219)
Para Plotino e Jung, então, a consciência é dependente da imaginação que, por sua vez, é direcionada pelas funções corporais e pela atenção. O centro subjetivo do ser humano aquilo que denominamos eu - nada mais é que uma função do imaginário. Os processos inconscientes estão fora de seu acesso e as imagens são as únicas chaves de compreensão.

As imagens partem de um centro - que é o centro da própria alma - que reflete o self. Esse self é inconsciente e só é apreendido pelo esforço concentrado da atenção. Mas quanto à contemplação da imagem de Deus, é como se o centro do eu se sobrepussesse ao centro do universo e, assim, não houvesse mais sentido na separação entre sujeito e objeto. Quem contempla é o próprio self, através da nossa consciência, alcançando a "raiz da alma". (vide Plotino,1993:VI,9,10)

Por isso, na experiência do dia a dia o self é reduzido à manutenção do corpo, ocupando-se da sensação e do pensamento em termos de sujeito e objeto localizados em um espaço e um tempo determinados, quer dizer, reduz-se a um eu (ego) que responde a um nome em função de sua inserção social.

Mas sua raiz é atemporal e, assim, o eu subsiste apenas na phantasia (imaginação), como um núcleo de imagens da alma derivadas da percepção e da memória.

Para ambos, o selfé concebido segundo uma imago Dei, uma imagem de Deus, embora Jung tenha o cuidado de diferenciar o campo da Psicologia do da Teologia, o que é impensável em Plotino.

Quanto à anima mundi, a alma do mundo, embora exista uma discordância sobre a questão de sua substancialidade, poderia ser interpretada como uma noção similar à de inconsciente coletivo, como memória coletiva das imagens primordiais.

Certamente a base biológica e empírica da teoria junguiana não se coaduna ao espiritualismo de base mística da filosofia 
plotiniana, mas os pressupostos essenciais são os mesmos. Pois muitos dos argumentos biológicos em Jung surgem como uma maneira de conferir aos seus conceitos uma roupagem mais aceitável ao empirismo dominante, não sendo premissas necessárias para as suas teorias.

Assim, podería-se dizer que o campo de estudos privilegiado da psicologia junguiana é a análise das imagens arquetípicas e que a base de seu método é a intuição, ou seja, o pensamento noético aplicado às configurações simbólicas.

E se a dianoia (pensamento discursivo) presente nas Enéadas sobreviveu por tantos séculos foi devido às suas grandes intuições. Seus ensinamentos chegaram até nós como algo vivo. Seus reflexos estão não só nas idéias de Jung, mas também num sem número de correntes filosóficas e crenças religiosas ou esotéricas.

E o conceito para o qual os dois autores confluem é o de self, cuja abrangência ultrapassa o âmbito da análise da personalidade, envolvendo questões epistemológicas fundamentais, pois seria também o centro do cosmos.

Dessa forma, tanto para Plotino como para Jung, o homem privado de imagens é um estranho para si mesmo, inconsciente de sua existência, incapaz de aperceber sua constituição íntima.

Tal asserção - paradoxalmente - vale tanto para o homem de alma embrutecida num sentido negativo - quanto para o sábio que na contemplação do Absoluto, refletido em seu self, perde sua consciência e se une à totalidade do cosmos - tomada no aspecto positivo.

Nesse último caso, a atenção (phrontis) concentrada produz uma espécie de inconsciência que separa o homem superior de suas imaginações, como uma força psíquica que o conduz a níveis mais elevados de conhecimento.

\section{REFERÊNCIAS}

AUBENQUE, P.(1981) Plotino e o neoplatonismo. In: Châtelet, F. (org.). História da Filosofia 1: A filosofia pagã. Rio de Janeiro: Zahar.

BRÉHIER, E. (1977) História da Filosofia. v.1/2. São Paulo: Mestre Jou.

BRUN, J. (1981) O Neoplatonismo. Lisboa: Edições 70.

(1991) Epicure et les épicuriens. Paris: PUF.

HILLMAN, J. (1981) Estudos de psicologia arquetípica. Rio de Janeiro: Achiamé.

JACOBI, J. (1986) Complexo, arquétipo, símbolo na psicologia de C.G.Jung. São Paulo: Cultrix.

JUNG, C.G. (1975) Memórias, sonhos, reflexões. Rio de Janeiro: Nova Fronteira.

(1981) Estudos sobre psicologia analítica. Petrópolis: Vozes.

(1982) Aion. Estudos sobre o simbolismo do si-mesmo. Petrópolis: Vozes.

(1983) Psicologia da religião ocidental e oriental. Petrópolis: Vozes.

(1984) A natureza da psique. Petrópolis: Vozes.

.(1985) Mysterium coniunctionis. 2v. Petrópolis: Vozes.

(1986) Sincronicidade. Petrópolis: Vozes.

(1991) Tipos psicológicos. Petrópolis: Vozes.

(1994) Psicologia e alquimia. Petrópolis: Vozes.

PETERS, F.E. (1983) Termos filosóficos gregos. Um léxico histórico. Lisboa: Fundação Calouste Gulbenkian. 
PLOTINO. (1993) Ennéades. 6v. Trad. E.Bréhier. Paris: Les Belles Lettres.

SEGAL, R.A. (1995) The allure of Gnosticism: The Gnostic esperience in Junguian Psychology and contemporary culture. Chicago: Singer \& Stein.

SCHWYZER, H.R. (1960) 'Bewusst' und 'Unbewusst' bei Plotin. In: Sources de
Plotin, Genebra: Fondation Hardt, 342-378.

TORRENTS, J.M. (1990) Los Gnósticos. 2v. Madrid:Gredos.

WARREN, E.W. (1964) Consciousness in Plotinus. Phronesis, 9:86-95.

. (1966) Imagination in Plotinus. Classical Quarterly, 16:277-285. 